\title{
Applying Simulation to Advance Resilience of Historic Areas to Climate Change and Natural Hazards
}

\author{
Katharina Milde ${ }^{1^{*}}$, Sonia Giovinazzi², Daniel Lückerath ${ }^{1}$, Oliver Ullrich ${ }^{1}$, Maurizio Pollino², \\ Erich Rome ${ }^{1}$, Vittorio Rosato ${ }^{2}$ \\ ${ }^{1}$ Fraunhofer Institute for Intelligent Analysis and Information Systems IAIS, Schloss Birlinghoven, Sankt Augustin, \\ Germany; *katharina.milde@iais.fraunhofer.de \\ ${ }^{2}$ Italian National Agency for New Technologies, Energy and Sustainable Economic Development (ENEA), Lungotevere \\ Thaon di Revel, 76, 00196 Rome, Italy
}

\begin{abstract}
The EU-H2020 project $A R C H$ aims to develop and adapt tools and methods for assessing and improving the resilience of historic areas to climate-related and other natural hazards [1]. One of these tools is CIPCast, a scenario simulation and decision support system for the analysis and forecast of risks and vulnerabilities of critical infrastructure components and their interdependencies. In this paper, we describe the basic functionalities of CIPCast, as far as the application to seismic risk assessment is concerned and we provide an overview of the models behind it. Furthermore, a brief discussion on how we plan to extend CIPCast to model and simulate potential risks and impacts induced by climate change to historic areas, and how this is intended to support resilience assessment strategies, is provided in the conclusions.
\end{abstract}

\section{Introduction}

Historic towns, old urban quarters, villages and hamlets, as well as historic landscapes make up a significant part of Europe: Natural heritage sites cover roughly 18\% of the European land territory [2] and on average 22\% of the European housing stock was constructed before 1946 [3]. These historic areas are deeply embedded in larger urban and rural environments (in which $72 \%$ of the European population live [4]), serving a role in preserving local identity and personality as well as local knowledge, while relying on interdependent infrastructure services to keep functioning. Historic areas are a major component of quality of life and play an important role in society and community well-being [5], as well as providing important environmental and economic functions.

Although climate change has become one of the most significant and fastest growing threats to people and their cultural heritage [6] the impacts of climate-related and other natural hazards on historic areas have not been studied extensively enough [7], and disaster risk reduction seldomly registers as a priority area for management of World Heritage property [8].

Therefore, there is a need for specific methods and tools for climate change adaptation and disaster risk reduction that take the unique physical, environmental, economic, social, cultural, and governance aspects of historic areas, as well as the enabling conditions they provide for taking action into account.

The EU Horizon 2020 research project ARCH (Advancing resilience of historic areas against climate-related and other hazards) [1] aims to take a step in this direction by providing a suite of tools for assessing and improving the resilience of historic areas, combined within a unified disaster risk management framework.

One of the tools developed within the project is an extension of the scenario simulation and decision support system CIPCast [9] in order to enable the assessment of impacts and risks to historic areas induced by climate change and natural hazards. This is an essential input for assessing the resilience of historic areas and identifying suitable resilience building strategies.

This paper gives an overview on how CIPCast functions and describes the extensions necessary to maximize its utility in the project context. The first section (sec. 1) gives a brief introduction to the ARCH project, followed by a general overview of the basic functionalities of CIPCast (sec. 2) and how these can already be employed to assess damage and impacts induced by seismic hazards (sec. 3). Following these explanations, the planned extensions of CIPCast (sec. 4), and how its results supports re- 
silience assessments (sec. 5) are described, before the paper closes with conclusions and an outlook (sec. 6).

\section{The ARCH project}

Advancing resilience of historic areas against climaterelated and other hazards (ARCH) is an EU Horizon 2020 research project that aims to better protect historic areas from climate-related and other natural hazards induced risks. The project started in June 2019 and will run until May 2022.

Within a co-creation process, the project team of eleven research partners and the cities of Bratislava, Camerino, Hamburg, and València will create tools and methods to provide cities with better information and decision support for improving the resilience of historic areas. The results will be applied in pilot sites within the cities covering a diverse spectrum of historic areas: the historic old towns of Bratislava and Camerino, the Devin Castle ruin in Bratislava, the Speicherstadt and Kontorhaus World Heritage sites in Hamburg, as well as the La Huerta peri-urban farmland and Albufera national park in València. These areas are affected by a multitude of different hazards, amongst them earthquakes, heatwaves, fluvial and pluvial flooding, storm surges, erosion, and landslides.

The technical work in ARCH includes the preparation of a hazard object information management system that captures data on hazards and object conditions using newly deployed sensors and readily available open data platforms; an impact risk assessment framework that provides methods and tools for risk and impact assessment, including hazard models and scenario simulation for what-if analyses; the design of implementation pathways that identify potential resilience measures enriched with effectiveness scores, supported via a tool for graphical implementation planning; and a multi-stakeholder resilience assessment framework integrating the methods and tools as well as a platform for collaboration and sharing.

The remainder of this paper focuses on describing the simulation and decision support system adapted within the project and how this will be employed for the resilience assessment.

\section{CIPCast Simulation and Decision Support System}

CIPCast is a GIS-based Decision Support System (DSS) developed as part of the EU-funded FP7 project CIPRNet (Critical Infrastructures Preparedness and Resilience ResearchNetwork) [10]. CIPCast provides a database, an interoperable platform and a user-friendly WebGIS interface. These are conceived as a combination of free/open source software environments, for the real-time and operational (24/7) monitoring and risk analysis of built and natural environments, with special focus on interdependent critical infrastructures (such as electric power, water, telecommunication and road networks) and buildings [9][11][23].

CIPCast is based on a four-layer architecture:

- Within the data preparation layer basic data is collected, harmonized and organised for the following processing step.

- In the data repository layer, data and metadata are stored in a geospatial database implemented in PostgreSQL/PostGIS.

- Within the analysis and elaboration layer stored data and metadata are managed and published online to enable geo-processing and risk analysis.

- Within the front-end layer, data and functions from the previous layers are exposed to end-users via a WebGIS application.

Within this architecture, CIPCast provides five distinct functional blocks that feed each other:

- B1 - Monitoring of Natural Phenomena acquires data from different data sources.

- B2 - Prediction of Natural Events houses different hazard models to estimate the expected intensities for predictable events.

- B3 - Prediction of Damage Scenarios correlates the (estimated) hazard intensity with the vulnerability of elements located in an affected area to estimate potential direct damages (e.g. breakage of a transformer in an electric substation).

- B4 - Prediction of Impacts and Consequences correlates the potential direct damages to exposed elements with their (inter-)dependencies with other elements and the general system characteristics to estimate larger consequences (e.g. loss of service in an electrical network).

- B5 - Support of efficient strategies enables what-if analysis of different strategies to counter the effects of examined hazards.

The CIPCast GeoDatabase stores data related to ex- 
posed elements and hazards. For seismic hazards the database includes information on epicenter location, hypocenter depth and magnitude; for exposed elements it includes both static data, like structural characteristics of buildings, and dynamic data, like population dynamics. The data model used in the GeoDatabase differentiates between different classes of exposed elements, e.g. networks, like telecommunication, electricity, transport networks, and groups of buildings. Detailed information for exposed elements is stored to estimate vulnerabilities, e.g. build material, construction age, and number of inhabitants.

Currently, CIPCast includes hazard data collected from seismic sensors, weather stations (for precipitation, temperature, humidity, wind, etc.), and hydrometers (for inundation levels of river basins).

\section{CIPCast-ES for Seismic Risk Assessment in Italy}

CIPCast-ES is an extension of CIPCast specifically aimed at simulation of seismic hazards and at the assessment of related physical damage and impact scenarios [17]. This section provides an overview of the models embedded within CIPCast-ES that enable these functions and some explanatory case studies.

\subsection{CIPCast-ES Seismic Hazard assessment}

To allow the assessment and representation of ground motion and earthquake-induced geotechnical hazards, available data, layers and information were collated in the GeoDatabase.

This data was sourced from previous studies as well as from external web services. They include services provided by the Italian National Earthquake Center (http://cnt.rm.ingv.it/en) managed by the Italian national Institute of Geophysics and Volcanology INGV; hydrogeological risk maps provided by "Idrogeo" (https://idrogeo.isprambiente.it/), and a web platform on landslide and flood risk provided by the Italian Institute for Environmental Protection and Research ISPRA.

For assessing ground motion hazards CIPCast-ES includes the following data: known faults locations (see Figure 1); catalogues of historical earthquakes; and seismic microzonation maps. The latter provide, at the local scale, spatial information about the effect of the local geological conditions on ground-shaking.
For assessing earthquake-induced geotechnical hazards CIPCast-ES includes the following data: surface faulting; seismic-induced landslide potential (see Figure 1); seismic-induced rock-fall potential; liquefaction potential; and potential for permanent soil deformation.

Based on this data a seismic hazard simulation allows to model and represent the location, extension and intensity of expected ground shaking generated by real or user-defined (artificial) events.

The simulation of real events is undertaken to support emergency management. In this case, a quasi-real time estimation of the extent and severity of the seismic ground shaking after an earthquake event is fundamental to provide a rapid, efficient and effective response. The simulation of end-user defined events is instrumental to support risk mitigation planning as explained in Section 3.3.

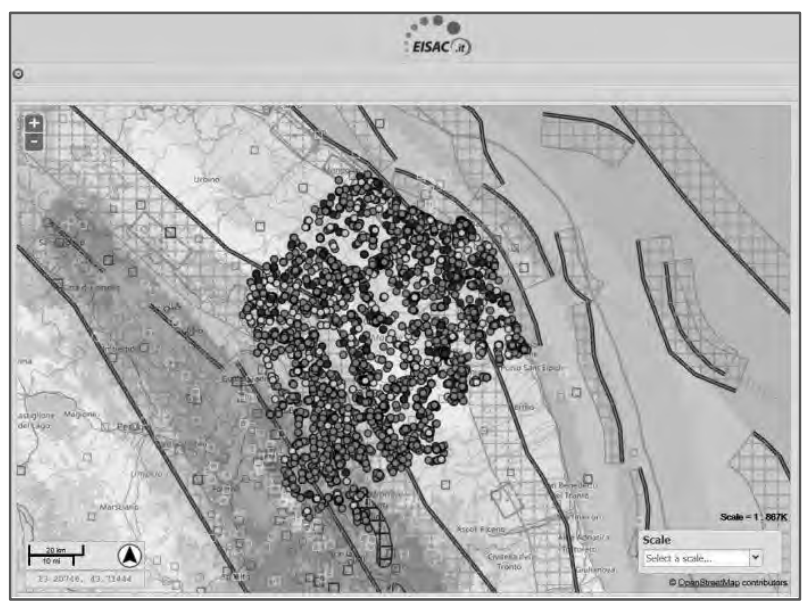

Figure 1: CIPCast-ES screenshot showing: seismic probabilistic hazard map and known-fault location maps from INGV, overlaid with cultural heritage assets (point locations).

In both cases the required inputs are:

- the location of the epicentre, i.e. latitude and longitude, $X_{E}, Y_{E}$;

- the depth of the hypocentre in kilometre $D_{H}$ $[\mathrm{km}]$; and

- the magnitude, $M$, expressed according to the Richter scale. 


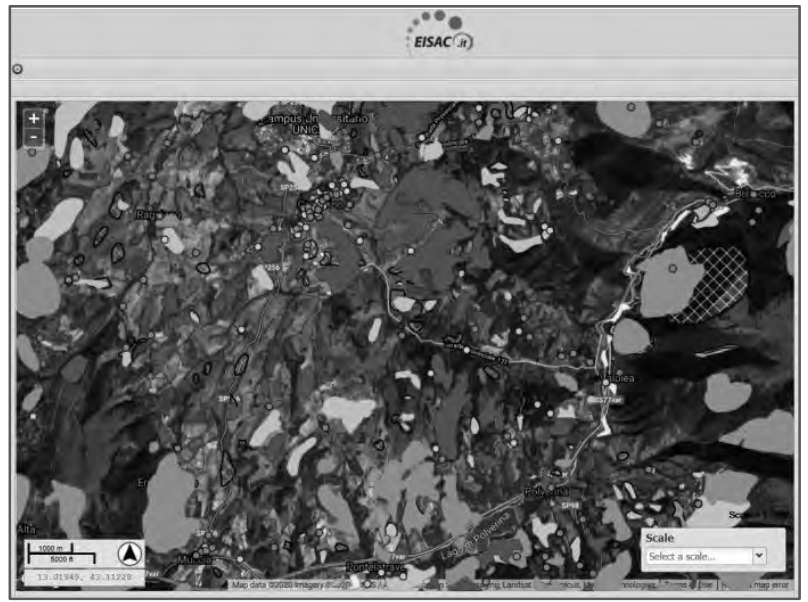

Figure 2: CIPCast-ES screenshot showing: Landslide risk maps from Italian P.A.I. "Piano Assetto Idrogeologico" overlaid with cultural heritage assets (area locations).

For real events, location and magnitude of any seismic event with a magnitude larger than $\mathrm{M}=3$ are acquired automatically and represented in real time within CIPCast-ES.

For end-user defined events, the user provides the relevant parameters, usually based on a catalogue of historic events and known fault locations (Figure 4), both accessible in CIPCast-ES.

Once the parameters are defined CIPCast-ES calculates where, to what extent and with which intensity ground shaking will propagate using Ground Motion Prediction Equations (GMPEs), or "attenuation" relationships. GMPEs provide a means of predicting the level of ground shaking and its associated uncertainty at any given site or location, based on magnitude, source-to-site distance (i.e. distance between the epicentre and the location of an exposed element), local soil conditions, typology of the fault mechanism, etc. GMPEs are empirical-based equations derived after post-processing of recorded accelerations or observed damages generated by historical earthquake events ${ }^{1}$.

In CIPCast-ES different GMPEs can be selected by the end-users allowing for the calculation and representation of seismic hazard maps with different metrics, i.e.:

- Macroseismic Intensity, I, [24];

- Peak Ground Acceleration PGA and Spectral Acceleration, $\mathrm{Sa}$ (T), [25];

- Peak Ground Velocity, PGV, [27]

- Spectral Displacements Sd (T), [27].

\footnotetext{
${ }^{1}$ An exhaustive compilation of GMPEs defined in the period
}

The selection of the most appropriate metric to represent the seismic hazard depends on the focus of the analysis; for example, $P G A$ and $S a(\mathrm{~T})$ have been observed to be more appropriate when the focus of the analysis is the structural performance of above-ground structures such as buildings while $P G V$ and $S d(\mathrm{~T})$ are suitable when the focus is on buried infrastructures. Macroseismic intensity on the other hand, is a qualitative descriptor of the effects of an earthquake at a particular location, as evidenced by observed damage on the natural and built environment and by the human and animal reactions at that location. Although a qualitatively metric, it is still used when adopting empirical-based models for assessing seismic vulnerability, such as the one described in section 3.2 for residential and monumental buildings.

Figure 3 provides an example of the official ground motion map after the L'Aquila earthquake on April 6, 2009 at 03:32 CEST, represented in PGA [\%g].

While official ground shaking maps are released by INGV around 45 minutes after an earthquake event occurs, the basic parameters necessary for simulation are usually published only a few minutes after an event. This allows to easily check and validate simulation results with actual event data.

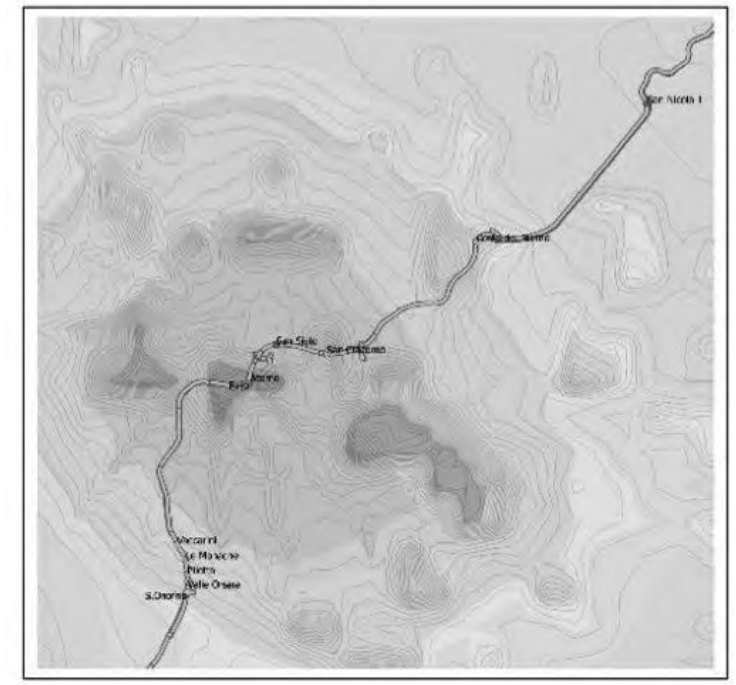

Figure 3: Official INGV ground motion map after April 6, 2009 L'Aquila earthquake overlaid with A24 Highway route.

For example, to simulate a ground-shaking map for the L'Aquila earthquake a user would choose the following parameters:

range 1964-2019 can be found here: http://www.gmpe.org.uk. 
- epicentre location $42.3476^{\circ} \mathrm{N}, 13.3800^{\circ} \mathrm{E}$,

- magnitude $M=6.3$,

- hypocentre $D_{H}[\mathrm{~km}]=9.46 \mathrm{~km}$.

Because CIPCast-ES allows to calculate ground shaking maps in quasi real time it is able to support emergency management operations with first estimates of the location, extent and level of ground shaking in the affected territories. Simulated maps are substituted in CIPCast-ES with official maps, as soon as they become available.

\subsection{CIPCast-ES Vulnerability and Physical Damage assessment for buildings}

To allow the assessment and representation of built-environment elements and of potentially exposed population the GeoDatabase includes: Administrative boarders (regions, municipalities and census tracks) and associated data on population (including gender, age, occupation, etc.) sourced from the Italian National Institute of Statistics; location and basic information on critical infrastructures like electrical transmission systems, gas transmission systems, main sources of electricity production, transport systems (road network, railways, airports), as well as the locations of strategic buildings like hospitals, barracks and schools.

Data about residential buildings is stored at single building level, when possible, or as aggregated data linked to geographical units otherwise. This includes data on construction age, construction material (masonry, reinforced concrete, timber, prefabricated,), type of structural system (e.g. frame versus shear walls for reinforces concrete buildings, bricks versus stones for masonry buildings), and adoption of seismic codes for design or retrofitting.

For the Prediction of Damage Scenarios (i.e. B3 Module) for buildings, the Macroseismic-Mechanical cross-calibrated Method [28][29] is implemented. This method allows to assess the seismic vulnerability of building groups, statistically aggregated in a geographical unit, and of single buildings as a function of their seismic vulnerability and of the ground-motion at their location (see Section 3.1).

The seismic vulnerability of buildings is measured by the vulnerability index $V$ and the ductility index $Q$, calculated based on building typology and constructive, geometrical or additional features able to affect and modify building behaviour when subjected to earthquake shaking. One way to calculate the vulnerability index $V$ is to combine a basic vulnerability index $V^{*}$ and a vulnerabil- ity index modifier $\Delta V$, where $V^{*}$ reflects the building typology and $\Delta V$ the sum of influencing features:

$$
V=V^{*}+\Sigma \Delta V
$$

Table 1 lists basic vulnerability indexes for different building categories (I to VII), construction materials (masonry or reinforced concrete) and construction periods. Figure 3 shows an example visualisation of vulnerability indexes on census tract level.

\begin{tabular}{llllll}
\hline & Masonry & V* & RC & V* \\
\hline I & $<1919$ & 0.79 & & - & - \\
\hline II & $1919-1945$ & 0.73 & & - & - \\
\hline III & $1945-1971$ & 0.69 & V & $<1971$ & 0.59 \\
\hline IV & $>1971$ & 0.65 & VI & $1971-1981$ & 0.55 \\
\hline & - & - & VII & $>1981$ & 0.42
\end{tabular}

Table 1: Basic vulnerability indexes $V^{*}$ for different building categories, construction periods and construction material. RC: Reinforced Concrete

Once the seismic vulnerability is assessed, the expected damage can be estimated as follows:

$$
\mu_{D}=2.5\left[1+\tanh \left(\frac{I+6.25 V-13.1}{Q}\right)\right]
$$

where:

- $\mu_{D}$ is the average expected damage for a group of buildings or an individual building;

- $V$ is the value of the vulnerability index;

- $Q$ is the ductility index assumed to be 2.3 for ordinary building categories like the ones from Table 1;

- I is the Macroseismic Intensity as described in the previous section.

\begin{tabular}{ll}
\hline$D_{0}=\mu_{D}<0.5 ;$ & $D_{3}=2 \leq \mu_{D}<3 ;$ \\
\hline$D_{1}=0.5 \leq \mu_{D}<1 ;$ & $D_{4}=3 \leq \mu_{D}<4 ;$ \\
\hline$D_{2}=1 \leq \mu_{D}<2 ;$ & $D_{5}=4 \leq \mu_{D} \leq 5$.
\end{tabular}

Table 2: Categorization of expected damages based on [30]

In order to categorize the expected damage $\mu_{D}$ the EMS-98 damage grade scale [30] is applied. This scale differentiates between six different levels $D_{k}$ : $D_{0}$ no damage, $D_{1}$ slight, $D_{2}$ moderate, $D_{3}$ heavy, $D_{4}$ very heavy, $D_{5}$ collapse/destruction. Table 2 lists how expected damages are categorized and Figure 4 shows an example visualization on census tracks level. 


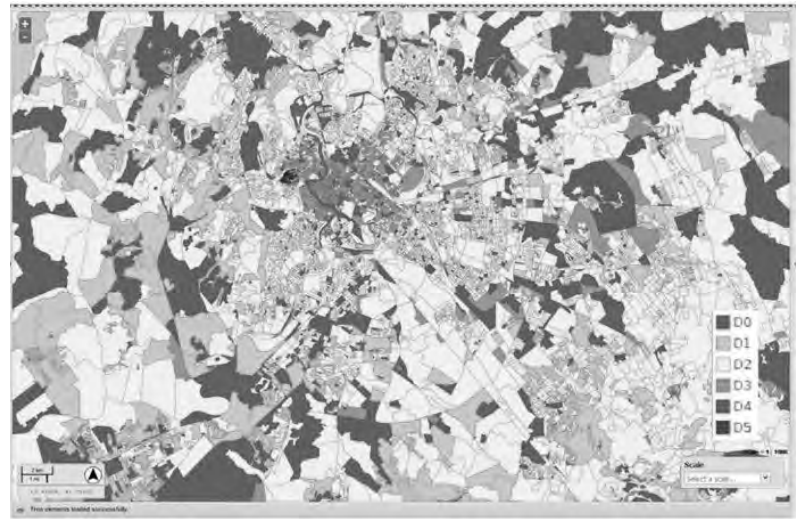

Figure 4: Example of the earthquake-induced damage assessment at census track levels [29]

\section{CIPCast Extensions for ARCH}

In order to employ CIPCast in ARCH, the GeoDatabase will be extended to include maps and data representing historic areas and heritage buildings, classified into moveable heritage, archaeological resources, buildings and structures, cultural landscapes, associated and traditional communities and intangible heritage as described in [31].

To allow the assessment of climate change induced scenarios the GeoDatabase will need to be extended to include related hazard maps (e.g. for floods or extreme temperatures) under different climate scenarios. These maps will be derived from numerical simulations, climate hazard indicators, optical/thermal earth observation maps, high-resolution aerial and satellite maps, and from existing data services, e.g. Copernicus Climate Change Service [21].

\subsection{CIPCast extensions for assessing damage to historic buildings}

In order to estimate seismic damages to historical buildings the same function as for residential building (see equation 2) will be employed, using adapted $V$ and $Q$ index values. These values will be calibrated using earthquake-induced damage sustained by cultural heritage areas and buildings during the last twenty years.

It is important to note that a vulnerability index assigned to a monument simply by a typological classification represents an average value that does not account for the distinctiveness of the single building and does not allow singling out the most vulnerable structures among buildings of the same type. Therefore, the vulnerability assessment will be refined to reflect peculiar characteristics and features of historic buildings that might increase or decrease their vulnerability, e.g. via a survey that collects relevant parameters like maintenance conditions, quality of materials, structural regularity (in plan and in elevation), size and slenderness of relevant structural elements, possible interaction with adjacent structures, presence of retrofitting interventions, etc.

\subsection{CIPCast extensions for assessing climate change induced scenarios}

To allow for the simulation of damage and impact scenarios induced by climate-related hazards CIPCast needs to be extended with the capability to manage additional input data and additional simulation modules. The basic framework for CIPCast-CC (CIPCast Climate Change module, also referred to as ARCH DSS), will be similar to CIPCast-ES, i.e. physical damage induced by climate change on the built environment in historic areas will be assessed as a function of hazard, exposure and vulnerability. Specifically, ARCH DSS will include

- models for index-based vulnerability assessment at area and single building level (e.g. compare to [32][33]);

- models for physical damage assessment that combine a) hazards parameters; b) position and typology of heritage; and c) heritage vulnerability; and

- models for the estimation of functional, economic and societal impacts.

For the latter, cause-effect models are necessary, which can for example be derived by developing impact chains in multi-stakeholder workshops [34].

\section{Integration of CIPCast in the $\mathrm{ARCH}$ resilience assessment}

The ARCH project adapts the Urban Adaptation Cycle [35] to describe the resilience management process of historic areas. One step in this process is the assessment of hazards, vulnerabilities, risks, and resilience. The resilience assessment is based on the UNDRR Disaster Resilience Scorecards for cities [22] and buildings [35]. As part of the resilience assessment, users need to identify the most relevant hazard and risk scenarios for the historic area that is being assessed and should formulate resilience enhancing measures to eliminate resilience weak spots. Here, CIPCast will be employed to enable users to identify and simulate hazard scenarios, assess potential impacts and identify the most suitable measures to raise the resilience. 
The resilience assessment will be implemented as a web-based, semi-quantitative, multi-stakeholder self-assessment questionnaire that covers topics like governance processes to increase resilience, financing resilience, restoration and recovery for resilience, social justice in resilience management, and environmental issues in resilience. The resilience assessment is intended to guide users through this process, link to relevant tools at appropriate steps and support better coordination among relevant actors. The result of the resilience assessment will be given as a weighted resilience score for the historic area with linked resilience enhancing measures and additional information for decision-makers.

\section{Conclusion}

We described the planned use of modelling and simulation for assessing the resilience of historic areas against the impact of climate change and other extreme events. Aims and scope of the ARCH project were introduced, the CIPCast Simulation and Decision Support System, its planned extensions, as well as a brief application example were described.

As next research steps, CIPCast will be extended as described in section 4 . The hazard models and simulation approaches will be integrated with a database of resilience building measures to support formulation and comparison of resilience building strategies. These functionalities will be integrated in a resilience assessment framework based on the UNDRR Disaster Resilience Scorecards for cities and buildings that include further - nonphysical - resilience aspects (e.g. community resilience) to support the formulation of comprehensive resilience actions plans for historic areas.

\section{Acknowledgements}

This paper has been prepared in the framework of the European project ARCH - Advancing Resilience of historic areas against Climate-related and other Hazards. This project has received funding from the European Union's Horizon 2020 research and innovation programme under grant agreement no. 820999. The sole responsibility for the content of this publication lies with the authors. It does not necessarily represent the opinion of the European Union. Neither the EASME nor the European Commission are responsible for any use that may be made of the information contained therein.

\section{References}

[1] ARCH Advancing Resilience of Historic Areas Against Climate-related and Other Hazards, https://savingculturalheritage.eu/, accessed on Sep. 15, 2020.

[2] European Commission, Europe's Cultural and natural Heritage in Natura 2000. Publications Office of the European Union, Luxembourg, 2018.

[3] Nicol S., Roys M., Ormandy D., Ezratty V. The cost of poor housing in the European Union. University of Warwick, 2016

[4] Nabielek K., Hamers D., Evers D. Cities in Europe Facts and Figures on cities and urban areas, PBL Publishers, The Hague, 2016.

[5] Tweed C., Sutherland M. Built cultural heritage and sustainable urban development. Landscape and urban planning, 2007, 83(1): 62-69.

[6] ICOMOS, 19GA 2017/30, Resolutions of the $19^{\text {th }}$ General Assembly, 11.-15.12.2017, New Delhi, India.

[7] Bigio A. G., Ochoa M. C., Amirtahmasebi R. Climateresilient, Climatefriendly World Heritage Cities. Urban Development Series Knowledge Papers, Bd. 19, World Bank, Washington, DC, 2014.

[8] Global Platform for Disaster Risk Reduction, Heritage and Resilience. Issues and Opportunities for reducing disaster risks, Global Platform for Disaster Risk Reduction, Geneva, Switzerland, 2013.

[9] Di Pietro, A., Lavalle, L., La Porta, L., Pollino, M., Tofani, A., Rosato, V.: Design of DSS for Supporting Preparedness to and Management of Anomalous Situations in Complex Scenarios. in: Setola R., Rosato V., Kyriakides E., Rome E. (Eds.): Managing the Complexity of Critical Infrastructures, A Modelling and Simulation Approach, Springer, 2016, pp 195-232.

[10] Rome E., Doll T., Rilling S., Sojeva B., Voÿ N., Xie J.: The Use of What-If Analysis to Improve the Management of Crisis Situations Chapter 10, in: Setola R., Rosato V., Kyriakides E., Rome E. (Eds.): Managing the Complexity of Critical Infrastructures, A Modelling and Simulation Approach, Springer, 2016.

[11] Giovinazzi, S., Pollino, M., Ciarallo, F., Rosato, V., Luigi La Porta, L., Di Pietro., A., Clemente, P., Buffarini, G., (2019). A Decision Support System for the Emergency Management of Highways in the Event of Earthquakes. ANIDIS XVIII, Ascoli Piceno, Settembre 2019.

[12] INSPIRE Knowledge Base, https://inspire.ec.europa.eu/, accessed on March 4, 2020.

[13] D'Alessandro, A., Costanzo, A., Ladina, C., Buongiorno, F., Cattaneo, M., Falcone, S., La Piana, C., Marzorati, S., Scudero, S., Vitale, G., Stramondo S., and Doglioni C.. Urban Seismic Networks, Structural Health and Cultural Heritage Monitoring: The National Earthquakes Observatory (INGV, Italy) Experience. Front. Built Environ., 05 November 2019. 
https://doi.org/10.3389/fbuil.2019.00127

[14] RAMSES Science for cities in transition, https://ramsescities.eu/home/, accessed on March 4, 2020.

[15] Giovinazzi, S., Pollino, M., Kongar, I., Rossetto, T., Caiaffa, E., Di Pietro, A., La Porta, L., Rosato, V., Tofani, A., Towards a Decision Support Tool for Assessing, Managing and Mitigating Seismic Risk of Electric Power Networks. Computational Science and Its Applications ICCSA 2017. In: Lecture Notes in Computer Science, Part III, LNCS 10406, pp. 399-414. Springer International Publishing, 2017a.

[16] Lagomarsino, S., Giovinazzi, S., Macroseismic and mechanical models for the vulnerability and damage assessment of current buildings. Bull. Earthq. Eng. 4, 415443, 2016.

[17] Matassoni, L., Fiaschi, A., Giovinazzi, S., Pollino, M., La Porta, L., Rosato, V., A geospatial decision support tool for seismic risk management: Florence (Italy) case study. Computational Science and Its Applications - ICCSA 2017. In: Lecture Notes in Computer Science. Part II, LNCS 10405, pp. 278-293, Springer International Publishing, 2017.

[18] D'Agostino, G., Di Pietro, A., Giovinazzi, S., La Porta, L., Pollino, M., Rosato, V., Tofani, A.. Earthquake Simulation on Urban Areas: Improving Contingency Plans by Damage Assessment. In: Luiijf E., ZÃåutautaiteÃá I., HaÃàmmerli B. (eds) Critical Information Infrastructures Security. CRITIS 2018. Lecture Notes in Computer Science, vol 11260, 72-83. Springer, Cham, 2019.

[19] Dolce, M., Nicoletti, M., De Sortis, A., Marchesini, S., Spina, D., and Talanas, F. Osservatorio sismico delle strutture: the Italian structural seismic monitoring network. Bull. Earthq. Eng. 15, 621-641. doi: 10.1007/s10518-015-9738-x, 2017.

[20] Giovinazzi, S., Di Pietro, A., Mei, M., Pollino, M., Rosato, V.: Protection of Critical Infrastructure in the Event of Earthquakes: CIPCast-ES. Proc. XVII ANIDIS Conference, Pistoia, Italy, 2017, pp. 62-70.

[21] Copernicus Climate Change Service, https://climate.copernicus.eu/, accessed March 4, 2020.

[22] United Nations office for Disaster Risk Reduction: Disaster Resilience Scorecard for Cities, https://www.undrr.org/publication/disaster-resiliencescorecard-cities, 2017.

[23] Taraglio, S., Chiesa S., La Porta, L., Pollino, M., Verdecchia, M., Tomassetti, B., Colaiuda, V., Lombardi, A.. Decision Support System for smart urban management: resilience against natural phenomena and aerial environmental assessment. International Journal of Sustainable Energy Planning and Management, Vol. 24, 2019.

[24] Faccioli, E., Cauzzi, C.. Macroseismic intensities for seismic scenarios estimated from instrumentally based correlations. In: Proc. of the First European Conference on Earthquake Engineering and Seismology - Geneva, Switzerland, 3-8 September 2006 . ECEES, 2006.
[25] Ambraseys, N.N., Simpson, K.A. And Bommer, J.J. Prediction of horizontal response spectra in Europe. Earthquake Eng. Struct. Dyn., 25: 371-400, 1996.

[26] Sabetta, F., Pugliese, A.. Estimation of Response Spectra and Simulation of Nonstationary Earthquake Ground Motions. Bull. Seismol. Soc. Am. 86, 337-352, 1996.

[27] Cauzzi, C., Faccioli, E.. Broadband (0.05 to 20 s) prediction of displacement response spectra based on worldwide digital records. J Seismol 12, 453, 2008.

[28] Giovinazzi S., The vulnerability assessment and the damage scenario in seismic risk analysis, Ph.D The-sis of the doctoral course "Risk Management on the built environment" jointly organized by University of Florence (I) and TU-Braunschweig (D), 2005.

[29] Lagomarsino, S., Giovinazzi, S. Macroseismic and mechanical models for the vulnerability and damage assessment of current buildings. Bull Earthquake Eng 4, 415-443 (2006). https://doi.org/10.1007/s10518-0069024-z

[30] Grünthal G (ed) European Macroseismic Scale 1998 (EMS-98). Cahiers du Centre Européen de Géody-namique et de Séismologie 15, Centre Européen de Géodynamique et de Séismologie, Luxembourg, 99 p, 1998.

[31] V. Rebollo, V. Latinos, I. Balenciaga, R. Roca. ARCH D7.2 Mapping and characterisation of good practices in cultural heritage resilience. ARCH H2020 Project GA No. 820999, https://savingculturalheritage.eu/resources/deliverables (accessed on September 15, 2020), 2020.

[32] RESIL, KP, NCRS, ENG, INOV, TROIA, BU, UWA, D6.6: STORM Damage Assessment and Decision Support Services, STORM H2020 Project Grant Agreement No.: 700191, 2016.

[33] A Chiabrando, F., Colucci, E. \& Lingua, A., Matrone, F., Noardo, F., Spano, A., A European Interoperable Databade (EID) to increase resilience of cultural heritage. ISPRS Journal of Photogrammetry and Remote Sensing. XLII. 151-158. 10.5194/isprs-archives-XLII-3-W4-1512018, 2019.

[34] Lückerath, D., Streberova, E., Bogen, M., Rome, E., Ullrich, O., Pauditsova, E.: Climate Change Impact and Vulnerability Analysis in the City of Bratislava: Application and Lessons Learned. In: Nadjm-Tehrani S. (ed) Critical Information Infrastructures Security. CRITIS 2019. Lecture Notes in Computer Science, Vol. 11,777. Springer, 2019, pp. 83-94

[35] European Climate Adaptation Platform Climate-ADAPT https://climate-adapt.eea.europa.eu/knowledge/tools/urban-ast, (accessed Sep 15, 2020), partnership between the European Commission and European Environment Agency.

[36] UNDRR ARISE, Disaster resilience scorecard for industrial and commercial buildings. For use by building owners, operators and managers, https://www.preventionweb.net/publications/view/69845 (acc. Sep 14, 2020) 